\title{
Learning in planarians as a function of interstimulus interval'
}

\author{
Frank J. Vattano and John W. Hullett \\ UNIVERSITY OF DENVER
}

\begin{abstract}
Efficiency of classical conditioning of 72 planarians was studied as a function of the interstimulus interval. Results indicate that the most meaningful response measure is the longitudinal body contraction. Two forward conditioning groups were significantly superior to two backward conditioning, one simultaneity, and one pseudoconditioning control group.

\section{Problem}

Recent investigations in the conditioning of planarians indicate that at this phylogenetic level learning is indeed possible (Thompson \& McConnell, 1955; McConnell, 1959; Jacobson, 1963). Other investigators (Halas, 1961; James, 1964) have challenged this thesis on the basis of a sensitization interpretation. The controversy between the different interpretations of McConnell (1964) and James (1964), is an important one in light of the recent work on memory transfer (McConnell, 1962; Corning \& John, 1961).

The present investigation was designed to apply a rather well established conditioning parameter to the flat worm to see if it also applied at this phylogenetic level. The parameter chosen was the interstimulus interval (ISI). The ISI has been shown to be a relatively stable parameter in human learning (Jones, 1961) and also displays a degree of order phylogenetically (Vattano, 1962). Also manipulation of the ISI allows for a comparison of forward versus backward conditioning; backward conditioning being a less efficient method of establishing a conditioned response (Lawson, 1960). It would follow that if flat worms are indeed capable of "true" learning their behavior should be some function of the interval between the onset of the conditioned stimulus and the onset of the unconditioned stimulus. All studies reviewed by the present author have employed a delayed conditioned paradigm with a 2 sec. ISI in the forward relationship.

\section{Method}

The Ss were 72 planarians, dorotocephala, obtained from the Turtox laboratories $15-20 \mathrm{~mm}$ in length. The animals were divided into six groups of 12 animals each. The different experimental conditions are presented in Table 1 .

Table 1. Experimental Conditions

\begin{tabular}{|c|c|c|c|}
\hline Group & $\mathrm{N}$ & $\begin{array}{c}\text { Duration of } \\
\text { Light (CS) }\end{array}$ & $\begin{array}{l}\text { Duration } \\
\text { Shock (U }\end{array}$ \\
\hline$I$ & 12 & 3 sec. & I sec. \\
\hline II & 12 & $2 \mathrm{sec}$. & $1 \mathrm{sec}$. \\
\hline III & 12 & 1 sec. & 1 sec. \\
\hline IV & 12 & 1 sec. & 2 sec. \\
\hline V & 12 & 1 sec. & 3 sec. \\
\hline VI & 12 & $2 \mathrm{sec}$. & $2 \mathrm{sec}$. \\
\hline
\end{tabular}

\section{Table 1.}

Psychon. Sci., 1964, Vol. 1.
The apparatus consisted of two white milk plastic training troughs 12-in long with a rounded out center 1/2-in wide and 1/2-in deep. Solder electrodes were affixed to each side of the troughs. The CS consisted of two 100-w incandescent bulbs approximately 6 in above the troughs. The UCS consisted of a $.3 \mathrm{ma}$ d.c. shock with $.75 \mathrm{v}$ delivered by an Applegate shock stimulator model No. 228. The anode and cathode could be switched to either side of the troughs. The CS and UCS durations and ISI's were controlled automatically by means of a series of relay switches allowing for consistent, accurate stimulus presentations calibrated by a Standard Electric timer, Model S-1. The conditioned paradigm was of the delayed type where the onset of the first stimulus (CS for forward, UCS for backward) overlapped and terminated with the second stimulus (UCS for forward, CS for backward). For Group III the light (CS) and shock (UCS) came on for a duration of $1 \mathrm{sec}$. and terminated together. For Group VI (the control group) the duration of the CS and UCS was 2 sec.

All animals in all groups were given 275 trials, the first 25 of which were adaptation trials to the light alone prior to light-shock conditions. Animals in groups I through $\mathrm{V}$ were then given 250 paired light-shock acquisition trials with the appropriate intervals as indicated in Table 1. Group VI animals were given 125 light presentations and 125 shock presentations presented in a random order. The intertrial interval for all groups was a minimum of $1 \mathrm{~min}$., to allow for proper recovery from the shock.

After the acquisition trials, all animals in all groups were given 25 test trials to the light alone with an intertrial interval of $1 \mathrm{~min}$. During the acquisition training, animals were run in groups of six in each trough. The anode and cathode switch was alternated on every other trial in an attempt to control for an equal number of cathode stimulations. In an absolute sense this was impossible, due to the random direction orientation of the six animals in the trough during acquisition. During test trials, animals were run individually. The entire running period lasted 16 days with half of the Ss in all six groups run the first eight days, and the last half of the Ss in 
Table 2. Mean Number of Responses (Turns and Contractions) Recorded During 25 Test Trials

\begin{tabular}{|c|c|c|c|c|c|c|}
\hline GROUP & I & II & III & IV & $\mathrm{V}$ & VI \\
\hline Turns & 13.08 & 10.67 & 6.67 & 9.25 & 8.58 & 10.33 \\
\hline Contractions & 4.08 & 3.58 & 1.17 & .83 & .83 & 1.42 \\
\hline
\end{tabular}

each group run the last eight days. All Ss were given 50 trials daily, with a 5 min. rest period after the first 25 trials. On the last day of running, which was the test day, all animals in all groups received their last 25 acquisition trials prior to the 25 test trials with a $5 \mathrm{~min}$. rest period between trial sets.

\section{Results}

The results in terms of mean number of cephalic turns and longitudinal contractions during the 25 test trials for all groups are presented in Table 2.

Turns and Contractions were analyzed separately. An analysis of variance over the different conditions indicated a significant effect for turns $(F=2.52 ; d f=5,60$; $\mathrm{p}<.05)$ and for contractions $(\mathrm{F}=2.54 ; \mathrm{df}=5,60 ; \mathrm{p}<.05)$. Since the experiment was run over a two week period with half of the Ss run one week and half the next, an analysis comparing the time was run and was found to be nonsignificant. Individual comparisons of groups using Newman-Keuls technique indicated that for turns the only significant comparison was between groups I and III. All other comparisons employing cephalic turns were not significant. The analysis of contractions, however, indicated significant t's between groups I and II with all other conditions at less than the .01 level of significance (Newman-Keuls). Also a combined forward (Groups I and II) vs. a combined backward (Groups IV and V) analysis resulted in significant differences at less than the .01 level of significance (Scheffe's technique; Winer, 1962).

Considering the contractions, both forward conditioning groups are superior in performance than the backward conditioning groups as well as the simultaneity and control groups. The poor performance under the simultaneity condition (Group III) is in keeping with most conditioning data.

\section{Diseussion}

The results provide partial evidence for conditioning in the "true" sense, in that the two forward groups were significantly different from all other groups. However, it will be noted that the control group performance was surprisingly good, in spite of the fact that this group received half the number of lights and shocks. Perhaps animals at this phylogenetic level are capable of sustaining much longer intervals than the $2 \mathrm{sec}$. maximum set by this study. If under the $60 \mathrm{sec}$. intertrial interval employed in the control group, planarians are indeed capable of establishing an association between the light and shock (though unpaired), it would not be unlikely that a longer interval than 2 sec. might show even more efficient performance.

The surprisingly small number of absolute response contractions compared with results of other investigations can probably be accounted for by the different criterion of conditioning. Practically all studies reported thus far in the literature have employed an acquisition criterion of conditioning. That is, the UCS (shock) was always presented even during testing. Anticipations to the shock during the CS period alone (before shock) were employed as conditioned responses. In the present study the CS alone was presented during test trials. Also, during the adapatation period most animals displayed an unconditioned response to the light which manifested itself in a cephalic turn; whereas longitudinal body contractions were never given to the light during adaptation. It appears on the basis of the present investigation that the contraction response is a more valid measure of conditioning than is the cephalic turn.

\section{Referenees}

CORNING, W. C., \& JOHN, E. R. Effect of ribonuclease on retention of conditioned response in regenerated planarians. Science, 1961, 134, 1363-1365.

HALAS, E. S. Types of response elicited in planaria by light. J. comp. physiol. Psychol., 1961, 54, 302-305.

JACOBSON, ALLAN L. Learning in flatworms and annelids. Psychol. Bull., 1963, 60, 74-94.

JAMES, R. L., \& HALAS, E. S. No difference in extinction behavior in planaria following various types and amounts of training. Psychol. Rec., 1964, 14, 1-11. JONES, JOAN E. Contiguity and reinforcement in relation to CS-UCS intervals in classical aversive conditioning. Psychol. Rev., 1962, 69, 176-186.

LAWSON, REED. Learning and behavior. New York: McMillan Company, 1960.

MCCONNELL, J. V., JACOBSON, A. L., \& KIMBLE, D. $P$. The effects of regeneration upon retention of a conditioned response in the planaria. J. comp. physiol. Psychol., 1959, 52, 1-5.

McCONNELL, JAMES V. Memory transfer through cannibalism in planarians. J. Neuropsychiat., 1962, 3, 42-48.

MCCONNELL, JAMES V. On the turning of worms: A reply to James and Halas. Psychol. Rec., 1964, 14, 13-20.

THOMPSON, R., \& McCONNELL, J. V. Classical conditioning in the planaria, Dugesia dorotocephala. J. comp. physiol. Psychol., 1955, 48, 65-68.

VATTANO, FRANK J. Efficiency of GSR conditioning as a function of CS-UCS interval. Ph. D. Dissertation, the Ohio State University, 1962. WINER, B. J. Statistical principles in experimental design. New York: McGraw-Hill, 1962.

\section{Note}

1. This work was supported by Grant MH 08384-01 from the National Institute of Mental Health. The authors wish to thank Dr. Bernard Spilka for his assistance with the treatment of the data. 